\title{
ANALYSIS OF BIOMASSES FOR THEIR THERMOCHEMICAL TRANSFORMATIONS TO BIOFUELS
}

\author{
PUSHPA JHA ${ }^{1} \&$ BHAJAN DASS ${ }^{2}$ \\ ${ }^{1}$ Department of Chemical Engineering, SLIET, Longowal, India \\ ${ }^{2}$ Department of Chemical Engineering, Chandigarh University, Mohali, India
}

\begin{abstract}
Biomasses in the forms of agricultural and forestry residues are gaining attention as alternative sources of energy due to various limitations of conventional sources of energy. Their applications as energy sources should be renewable and eco-friendly. The selection of biomass needs pairing with a suitable thermochemical process for the generation of biofuels and their precursors. This article communicates the investigation of acacia nilotica branch, bagasse, berry branch, coconut coir, corn cob, cotton stalk, groundnut shell, rice husk, rice straw and wheat straw as biomasses, for their considerations to thermochemical transformations. The authors explored the residues for their bulk density, calorific values, proximate analysis, ultimate analysis, ash fusibility characteristics and thermogravimetric analysis. The bulk density and calorific values of materials considered were quite low compared to that of conventional solid fuels. Therefore, they required palletisation for their economical utilisation as feedstocks for thermochemical conversions to energy carriers. The proximate analysis indicated that the fixed carbon:volatile matter of acacia nilotica branch was highest at 0.35 , suggesting it as the most preferred feedstock for pyrolysis. The ultimate analysis showed that $\mathrm{H} / \mathrm{C}$ (molar element ratios) of all residues were near to a constant value indicating the emissions of volatiles/gases were close to same quality after their specific thermochemical transformation. Ash deformation and fusion temperatures of materials lied in the range of $900-1500^{\circ} \mathrm{C}$, fixing the operating temperature limits for their transformations through combustors and gasifiers. Thermogravimetric analysis in the $\mathrm{N}_{2}$ atmosphere indicated that the rate of pyrolysis was highest for all residues, in the temperature range of $300-500^{\circ} \mathrm{C}$, suggesting the sufficiency of one reactor to carry out pyrolysis for the individual biomass. Thus, the analysis of biomasses for their thermochemical transformations is the prerequisite for their effective utilisations. Keywords: ash deformation temperatures, ash fusion temperatures, biofuels, biomasses, bulk density, calorific values, proximate analysis, thermochemical transformations, thermogravimetric analysis, ultimate analysis.
\end{abstract}

\section{INTRODUCTION}

India has an ideal environment for biomass production due to its geographical location. As per record, the country generates more than 500 million tons of agricultural and forestry wastes under the category of biomass [1-2]. Rural population is mainly dependent on the biomass as a traditional fuel, which is utilised inefficiently and generates greenhouse gases [3]. A small percentage of the resource is utilised to generate electricity (which is less than $1 \%$ of the total electricity generation in the country) [2]. The surplus residues are just burnt as a solution to the disposal problem, causing massive air pollution in the surrounding areas. There is a great need to develop suitable technologies to utilise the abundant biomass resource available after its harvest. The knowledge of properties of biomass (which vary with geographical locations) is essential [4].

Energy generation by biomass is mainly through biochemical and thermochemical ways. Much has been reported about energy generation by biochemical means through fermentation and anaerobic digestion [5-8]. However, energy production through the thermochemical pathway is promising. Thermochemical transformation is a process of controlled heating or the oxidation of biomass to produce biofuels or its precursor [9-10]. These technologies can be applied to any type of biomass as a feedstock with the almost complete conversion with 
multiple by-products. Also, the conversions are independent of ambient conditions as the operations take place at a much higher temperature range [11].The thermochemical conversion technologies cover combustion, gasification pyrolysis and liquefication [12-16]. Combustion is considered an accessible bioenergy pathway all over the world [17]. A complete transformation of biomass yields heat energy due to oxidation of its carbon and hydrogen content, to $\mathrm{CO}_{2}$ and $\mathrm{H}_{2} \mathrm{O}$. Imperfect combustion results in environmental air pollutants, $\mathrm{CO}$ and particulate matters. Also, the presence of $\mathrm{S}$ and $\mathrm{N}$ may lead to the emissions of SOx and NOx gases [18]. Biomass gasification is the partial oxidation of the material with controlled process conditions to maximise the yield of gaseous products which are syngas or producer gas, rich in $\mathrm{CO}, \mathrm{H}_{2}, \mathrm{CH}_{4}$ and $\mathrm{CO}_{2}$ [11]. Pyrolysis is the thermal degradation of biomass in the absence/limited supply of oxygen to produce a mixture of solid, liquid and gas. The products of gasifiers and pyrolysers can be used directly as biofuels or cleaned/upgraded to fuels.

The performance of biomass-based combustors, gasifiers and pyrolysers depends upon the characteristics of the biomass as feedstocks used [3]. In general, the biomass (agricultural and forestry residues) consists of 50\% carbon, $6 \%$ hydrogen and $44 \%$ oxygen on a dry basis with moisture content up to $90 \%$, on a wet basis. Ash content varies from 0.5 to $22 \%$ [19]. Biomass needs to be characterised in terms of their bulk density, calorific values, proximate analysis, ultimate analysis, ash deformation and fusion temperatures and thermogravimetric analysis [3]. Bulk densities and calorific values of the residues decide about their transportation economics. Proximate analysis is the determination of percentages of volatile matter (VM) (gases and vapours driven off during pyrolysis), fixed carbon (FC) (non-volatile carbon) and ash on a dry basis [20]-[22]. Ultimate analysis expresses the composition of biomass in terms of percentages of carbon, hydrogen, nitrogen, oxygen and sulphur in the elemental form [11]. The estimation of sulphur in biomass may be ignored as it has negligible sulphur content. The rest is ash which is accurately determined in the proximate analysis. Ash deformation and fusion temperatures are established as per standard methods to fix the design temperatures of combustors and gasifiers. Thermogravimetric analysis of biomass describes its thermal degradation (in a controlled atmosphere) with temperature.

In this work, we investigated biomasses in the forms of agricultural and forestry wastes for their suitability for conversion to biofuels through thermochemical transformations of pyrolysis, gasification and combustion. Biomasses analysed were acacia nilotica branch (ANB), bagasse, berry branch, coconut coir, corn cob, cotton stalk, groundnut shell, rice husk, rice straw and wheat straw. The basis of analysis was investigations of bulk density, calorific values, proximate analysis, ultimate and associated properties, ash deformation and fusion temperatures and variation of weight remaining with temperature in the nitrogen atmosphere. Bulk densities and calorific values of all biomasses were low. Proximate and ultimate analysis results were categorised in low, medium and high ash biomasses. ANB had highest FC:VM. Hydrogen to carbon elemental ratios (H:C) for all biomasses were appreciably constant. Biomasses under investigations recorded lowest ash deformation temperature at $900^{\circ} \mathrm{C}$ and the highest ash fusion temperature at $1500^{\circ} \mathrm{C}$. Thermographs of biomasses in the nitrogen atmosphere had similar trends. Based on the observations and analysis of biomasses, authors suggest specific thermochemical conversions for their transformations to biofuels and its precursors.

\section{MATERIALS AND METHODS}

\subsection{Bulk densities and calorific values of biomasses}

Biomasses considered were subjected to the determinations of bulk densities through the standard method. A glass cylinder $(50 \mathrm{ml})$ was filled to a fixed volume of oven-dried biomass. 
The cylinder, along with the specific biomass, was tapped for 1-2 min to compact it [19]. Bulk density was determined using the following formula:

$$
\text { Bulk density }=\left(\mathrm{W}_{\mathrm{d}} / \mathrm{V}_{\mathrm{d}}\right) \times 1000 \mathrm{~kg} / \mathrm{m}^{3}
$$

where $\mathrm{W}_{\mathrm{d}}$ is the weight of the biomass $(\mathrm{g})$ and $\mathrm{V}_{\mathrm{d}}$ is the volume of packed biomass $\left(\mathrm{cm}^{3}\right)$.

The biomasses were also tested for their calorific values as per ASTM D2075-77 using calorie meter (IKA C 200 model).

\subsection{Proximate analysis of biomasses}

The proximate analysis was completed for the biomasses using ASTM D3173-75 (methods recommended for coal and sparkling fuel). It involved the determinations of VM, FC and ash content on a moisture-free basis [19]. The muffle furnace and hot air oven along with the electronic balance were used to complete the analysis.

\subsection{Ultimate analysis and associated properties of biomasses}

The ultimate analysis was undertaken using ASTM D3174-76 (Vario Micro CHNS superuser analyser) [19]. The diagnosis determined the elemental percentages of carbon, hydrogen and nitrogen along with the ash content (which was determined through proximate analysis as mentioned in Section 2.2) present in specific biomass. The difference took the oxygen content. Determination of sulphur was ignored as biomasses contain negligible sulphur [3]. Percentages of $\mathrm{H}$ and $\mathrm{C}$ (with atomic weights of $\mathrm{H}$ as 1.008 and $\mathrm{C}$ as 12.011) enabled the estimations of $\mathrm{H} / \mathrm{C}$ molar ratios of materials considered.

\subsection{Ash deformation and fusion temperatures of biomasses}

The ash deformation and fusion temperatures of biomasses were investigated based on the guidelines of ASTM D1857-03 [19]. The ash was taken in the form of a cone using a mould. The ash deformation temperature reached when the apex of cone started rounding off. Ash fusion temperatures of respective biomasses were recorded at higher temperatures when the ash mass took the form of a hemispherical lump. Both the temperatures were detected using AF-600 \& AF-700 (LECO).

\subsection{Generation of thermographs for biomasses}

Thermographs of all 10 biomasses were generated individually by taking $10 \mathrm{mg}$ of ground biomass sample in Perkin Elmer STA 6000 TGA, at a constant heating rate of $40^{\circ} \mathrm{C} / \mathrm{min}$, up to $1000^{\circ} \mathrm{C}$ [19]. The thermogravimetric analysis was undertaken in the presence of nitrogen gas.

\section{RESULTS AND DISCUSSION}

\subsection{Bulk densities and calorific values of biomasses}

Bulk densities of biomasses were determined, as explained in Section 2.1. It is the ratio of the bulk of particles of biomasses to the volume they occupy. The total volume included space occupied by particles, void volumes and internal pore volumes of the particles. The bulk densities of various biomasses were determined using Equation (1). All biomasses considered had low bulk density (Fig. 1). ANB had the highest bulk density $\left(207.3 \mathrm{~kg} / \mathrm{m}^{3}\right.$ ), whereas 


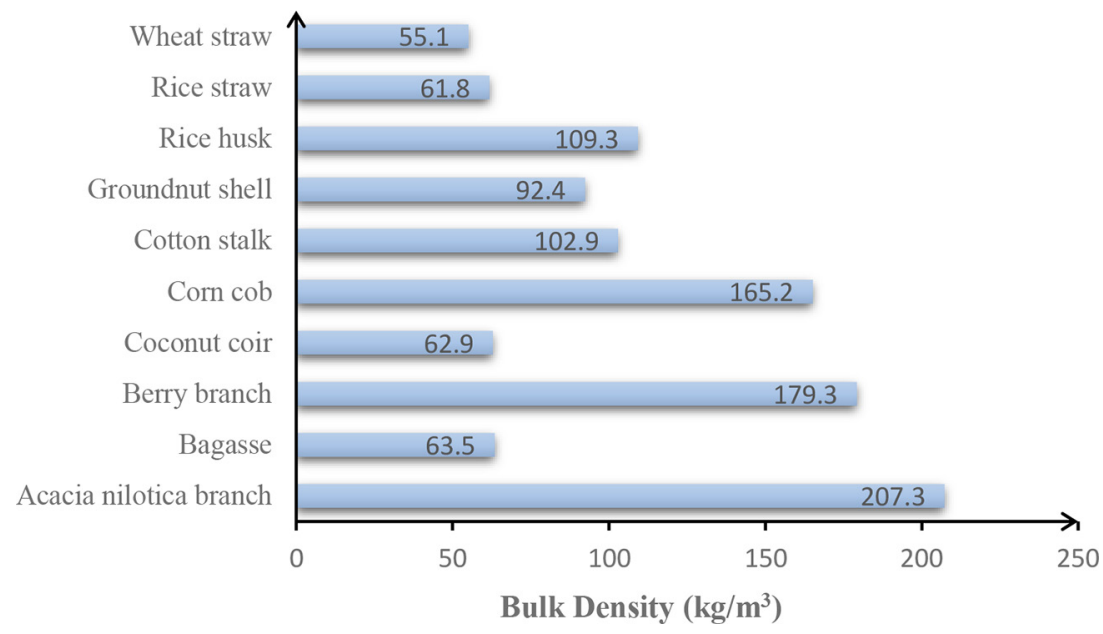

Figure 1: Bulk densities of biomasses.

wheat straw had the lowest value $\left(55.1 \mathrm{~kg} / \mathrm{m}^{3}\right)$. The results indicate that bulk densities of biomasses considered are little lower than the average density of wood, confirming that all residues require palletisation for their economical transportation [23]. Calorific values of biomasses indicate their gross heating values. They were estimated, as mentioned in Section 2.1. The calorific values are compared in Fig. 2. They are all close to $4000 \mathrm{cal} / \mathrm{g}$, which is lower than the reported value for wood $(4800 \mathrm{cal} / \mathrm{g})$ [3]. To make them more effective as fuel, they need palletisation [24].

\subsection{Proximate analysis of biomasses}

The biomasses were subjected to proximate analysis where they were subjected to investigations for the presence of moisture content, VM, FC and ash content (Table 1). As the moisture content keeps varying in biomass (due to variation in the surrounding atmosphere), the analysis was completed on a dry basis. The results were classified based on the extent of ash content: low ash, medium ash and high ash biomasses [3]. ANB, berry branch corn cob and cotton stalk were low ash biomasses having ash contents less than 5\%. Bagasse, groundnut

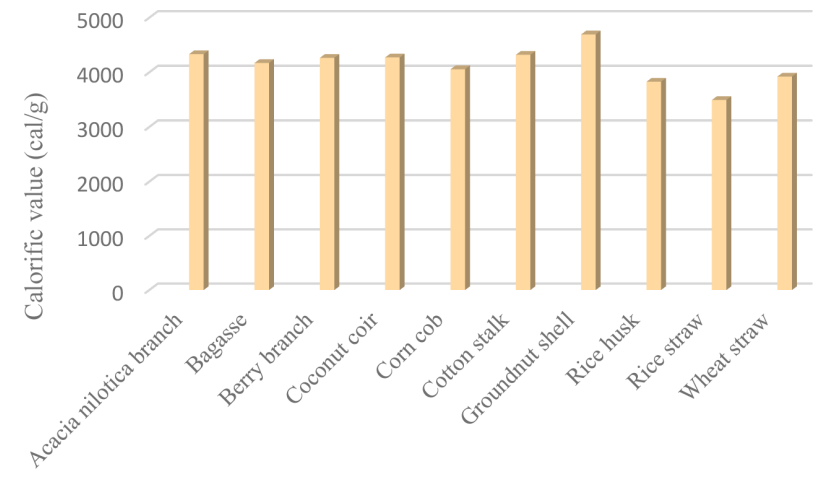

Figure 2: Calorific values of biomasses. 
Table 1: Proximate analysis of biomasses.

\begin{tabular}{|c|c|c|c|c|}
\hline Biomasses & VM $(\%)$ & FC (\%) & $\operatorname{Ash}(\%)$ & FC:VM \\
\hline \multicolumn{5}{|c|}{ Low ash biomasses } \\
\hline ANB & 72.03 & 24.97 & 3.00 & 0.35 \\
\hline Berry branches & 78.60 & 19.10 & 2.30 & 0.24 \\
\hline Corn cob & 78.51 & 18.63 & 2.86 & 0.24 \\
\hline Cotton Stalk & 76.00 & 20.24 & 3.76 & 0.27 \\
\hline \multicolumn{5}{|c|}{ Medium ash biomasses } \\
\hline Bagasse & 80.27 & 14.72 & 5.01 & 0.18 \\
\hline Groundnut shell & 72.70 & 21.20 & 6.10 & 0.29 \\
\hline Wheat straw & 72.50 & 17.60 & 9.90 & 0.24 \\
\hline \multicolumn{5}{|c|}{ High ash biomasses } \\
\hline Coconut coir & 70.13 & 16.70 & 13.17 & 0.24 \\
\hline Rice husk & 61.95 & 21.00 & 17.05 & 0.34 \\
\hline Rice straw & 65.50 & 14.65 & 19.85 & 0.22 \\
\hline
\end{tabular}

shell and wheat straw were medium ash biomasses with ash compositions in the range of $5-10 \%$, whereas coconut coir, rice husk and rice straw formed the category of high ash biomasses with ash contents greater than $10 \%$. The results suggest that higher ash content will increase the catalytic activity towards formations of char and gaseous products though pyrolysis of biomasses. Lower ash will promote the peak combustion rate of residues at higher temperatures while the same will promote gasification at the highest rate at lower temperatures [11]. FC:VM ratio of ANB is 0.35 , which is highest, whereas the same for bagasse is lowest at 0.18. Higher FC:VM implies higher formations of char and lower formations of gases in pyrolysis and gasification transformations. Hence ANB should be most preferred for char generation through pyrolysis, whereas bagasse should be utilised for gas generation through gasification [25].

\subsection{Ultimate analysis and associated properties of biomasses}

Ultimate analysis on biomasses was completed, as mentioned in Section 2.3. The results (Table 2) indicate appreciably high percentages of carbon and oxygen in the materials under consideration, justifying their application for energy generation [4]. The percentages of hydrogen in various residues are almost constant. The values lie in the range of $5.27 \%$ (rice husk) to $6.02 \%$ (corn cob). Calculating $\mathrm{H} / \mathrm{C}$ (molar element ratio) leads to the fact that they are almost constant at a value of 1.52 (Fig. 3). For convenience acacia nilotica branch, bagasse, berry branch, coconut coir, corn cob, cotton stalk, groundnut shell, rice husk, rice straw and wheat straw are abbreviated as ANB, Bag, BB, CNC, CC, CS, GNS, RH, RS and WS, respectively, in Fig. 3. Thus, we infer that thermochemical transformations of residues through gasification and combustion will produce the same quality of combustible gases if they are thermally treated with the same heating rate [3]. Percentages of nitrogen were less than $1 \%$ in most of the biomasses concluding the fact that NOx gases will be in traces if biomasses are subjected to thermochemical conversions. 
Table 2: Ultimate analysis.

\begin{tabular}{|c|c|c|c|c|}
\hline Biomasses & $\mathrm{C}(\%)$ & $\mathbf{H}(\%)$ & $\mathbf{N}(\%)$ & $\mathbf{O}(\%)$ \\
\hline \multicolumn{5}{|c|}{ Low ash biomasses } \\
\hline ANB & 47.42 & 5.79 & 0.87 & 42.92 \\
\hline Berry branches & 45.81 & 5.94 & 0.61 & 45.34 \\
\hline Corn cob & 46.46 & 6.02 & 0.36 & 44.29 \\
\hline Cotton Stalk & 46.04 & 5.71 & 0.47 & 44.01 \\
\hline \multicolumn{5}{|c|}{ Medium ash biomasses } \\
\hline Bagasse & 45.76 & 5.91 & 0.10 & 43.23 \\
\hline Groundnut shell & 50.58 & 5.72 & 0.57 & 37.03 \\
\hline Wheat straw & 40.36 & 5.28 & 1.44 & 43.02 \\
\hline \multicolumn{5}{|c|}{ High ash biomasses } \\
\hline Coconut coir & 46.52 & 5.50 & 0.17 & 34.64 \\
\hline Rice husk & 40.02 & 5.27 & 0.29 & 37.37 \\
\hline Rice straw & 36.98 & 5.46 & 0.63 & 37.08 \\
\hline
\end{tabular}

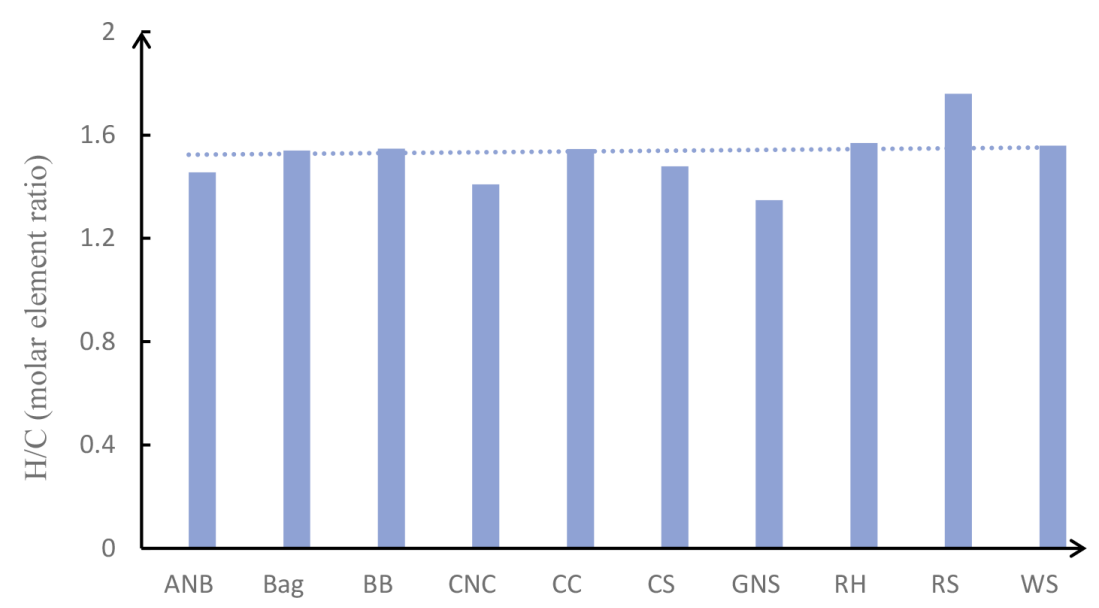

Figure 3: H/C (molar element ratio) of biomasses.

3.4 Ash deformation and fusion temperatures of biomasses

As mentioned in Section 2.4, ash deformation and fusion temperatures were determined using standard methods and shown in Fig. 4 (biomasses are abbreviated in the same way as explained in Section 3.3). As expected, ash fusion temperatures of all biomasses were higher than ash deformation temperatures. Ash deformation temperature of ANB, which is low ash biomass, is $1350^{\circ} \mathrm{C}$, whereas its ash fusion temperature is $1500^{\circ} \mathrm{C}$. Both the temperatures are among one of the highest for ANB. Thus, the biomass, ANB, is most suitable for combustion or gasification, because energy can be generated at the highest temperatures without the possibilities of clinker formations [11]. Thermochemical reactors should be designed in such a way that the temperatures within the converters do not rise beyond the ash deformation and fusion temperatures for specific biomass. 


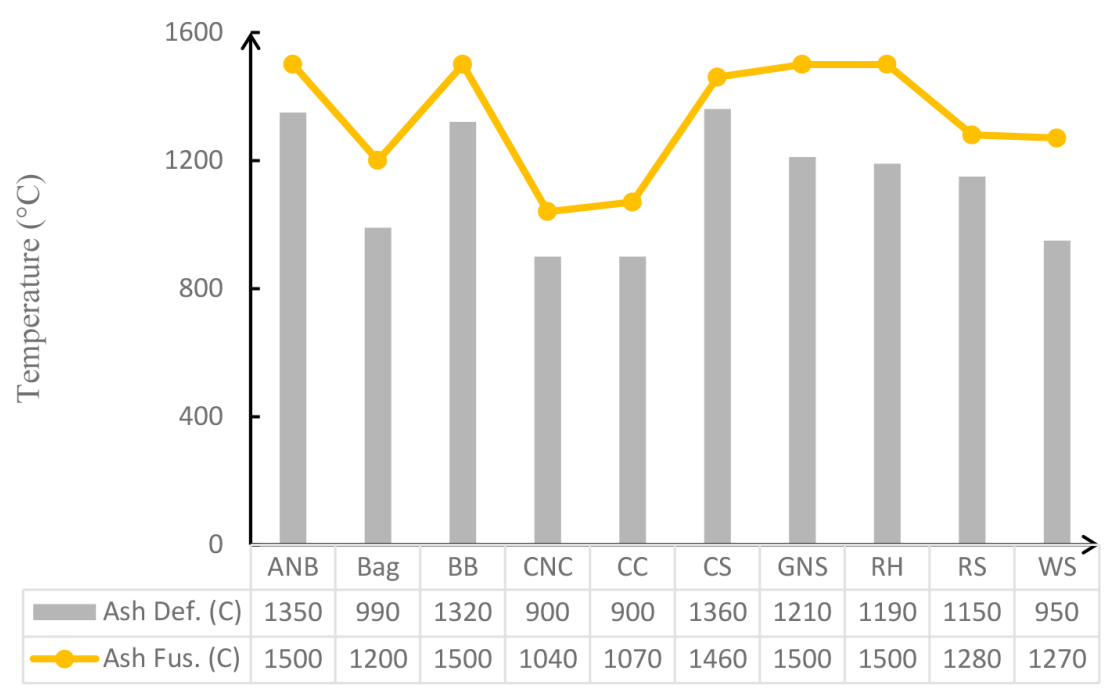

Figure 4: Ash deformation and fusion temperatures of biomasses.

\subsection{Generation of thermographs for biomasses}

Thermographs for biomasses (as explained in Section 2.5) were generated. The graphs are categorised under low ash (Fig. 5), medium ash (Fig. 6) and high ash (Fig. 7) biomasses. They show the variation of weight per cent remaining with temperatures. Drying of biomasses takes place till $100^{\circ} \mathrm{C}$. In all biomasses, torrefaction (low-temperature pyrolysis to remove moisture and volatiles) takes place in the temperature range of $200-300^{\circ} \mathrm{C}$. Also, for all residues weight per cent remaining starts falling at a much higher rate in the temperature range of $300-500^{\circ} \mathrm{C}$. After $500^{\circ} \mathrm{C}$, the rate of pyrolysis slows down and becomes constant beyond $600^{\circ} \mathrm{C}$. The data generated through thermogravimetric analysis can be used for estimation of the rate of pyrolysis and associated kinetic constants [26]. As temperature ranges for drying, torrefaction and pyrolysis, almost coincide for the individual biomasses under investigation, their pyrolysis may be carried out in the same converter.

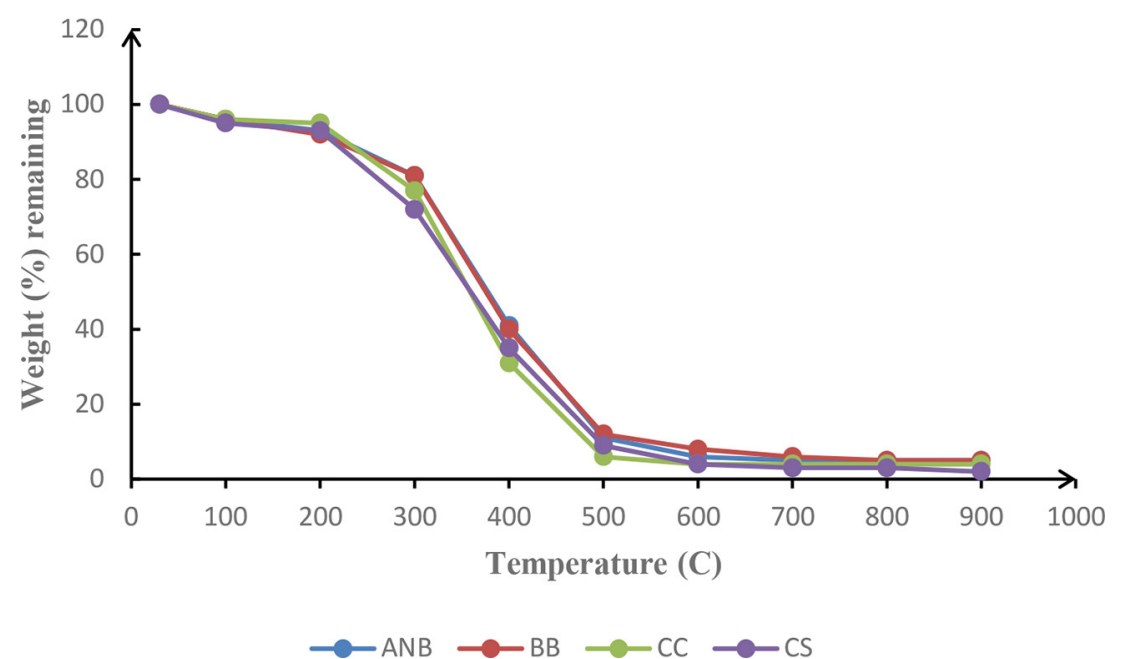

Figure 5: Thermographs of low ash biomasses. 


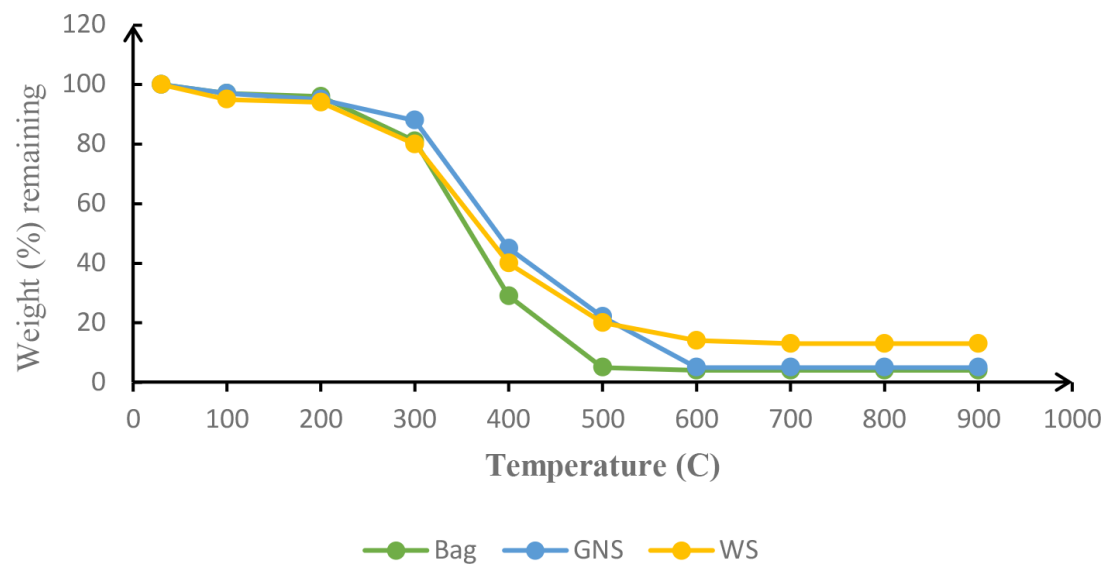

Figure 6: Thermographs of medium ash biomasses.

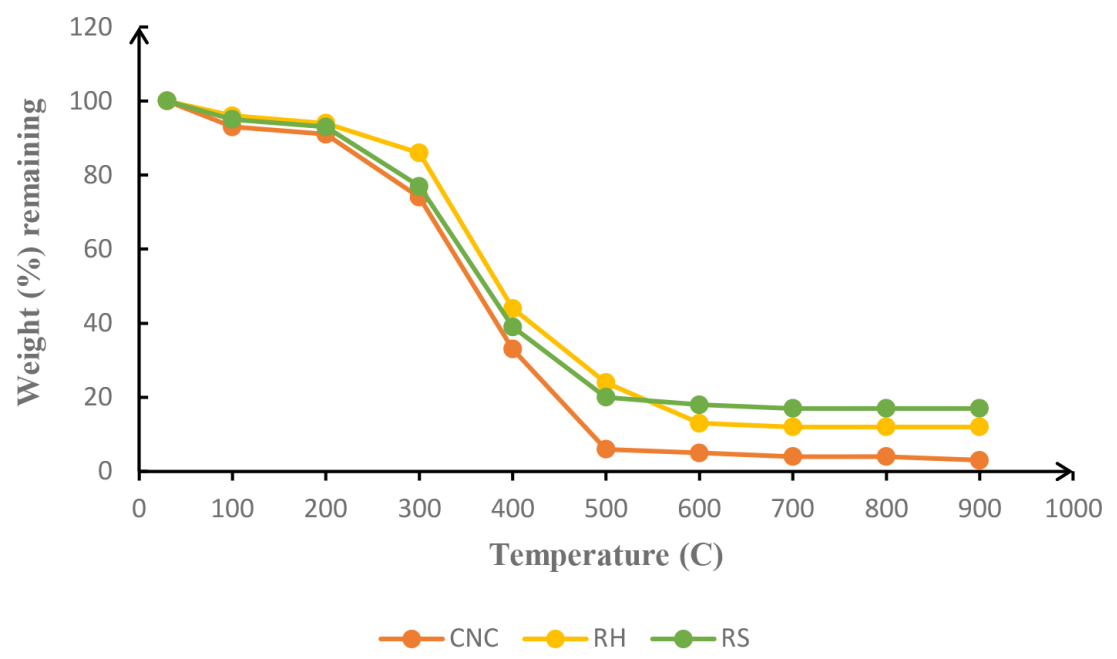

Figure 7: Thermographs of high ash biomasses.

\section{CONCLUSIONS}

Analysis of biomasses in terms of their bulk density, calorific values, proximate analysis, ultimate analysis, ash deformation and fusion temperatures and thermogravimetric analysis is prerequisite for their paring with a specific thermochemical conversion to a biofuel or its precursor. Biomasses considered need palletisation for their effective utilisation as biofuels. ANB as a residue has highest FC:VM, making it most suitable for the production of char, whereas bagasse has lowest FC:VM, suggesting the biomass should be most preferred for the gasification purpose. High percentages of carbon and oxygen in all biomasses confirm that they are suitable for their thermochemical transformations to biofuels. $\mathrm{H}: \mathrm{C}$ (molar element ratio) of all biomasses are approximately constant at 1.52, indicating that almost same quality of combustible gases/vapours will be generated by any biomass as a feedstock through a specific thermochemical transformation. Ash deformation and fusion temperatures were recorded in the range of $900-1350^{\circ} \mathrm{C}$ and $1040-1500^{\circ} \mathrm{C}$, respectively, which fixes the 
operating temperatures of combustors and gasifiers. Similar trends of thermographs for biomasses indicate that a single pyrolyser can be utilised for biomasses.

\section{ACKNOWLEDGEMENTS}

Authors express their gratitude to Central Power Research Institute, Bengaluru, India and SSS-NIRE, Kapurthala, Punjab, India for ash fusibility tests and thermogravimetric analysis of biomasses, for the publication.

\section{REFERENCES}

[1] Bhuvaneshwari, S., Hettiarachchi, H. \& Meegoda, J.N., Crop Residue Burning in India: Policy Challenges and Potential Solutions. International Journal of Environmental Research and Public Health, 16, pp. 1-19, 2019. https://doi:10.3390/ijerph16050832

[2] Bnapurmath, N.R, Yaliwal, V.S., Adaganti, S.Y.\& Halewadimath, S.S., Power Generation from Renewable Energy Sources Derived from Biodiesel and Low Energy Content Producer Gas for Rural Electrification. In Energy from Toxic Organic Waste for Heat and Power Generation, ed. Debabreta, B.,Woodhead Publishing: Cambridge, UK, pp. 151-194, 2019.

[3] Iyer, P.V.R., Rao, T.R. \& Grover, P.D., Biomass Thermo-Chemical Characterization, Chemical Engineering Department, IIT Delhi, 2002.

[4] Park, C.S., Roy, P.S. \& Kim, H.S., Current Developments in Thermochemical Conversion of Biomass to Fuels and Chemicals. Gasification for low-grade feedstocks. ed. Yongseung Yun, IntechOpen, pp. 19-41, 2018. https://dx.doi.org/10.5772/intechopen.71464

[5] Vermerris, W., Survey of genomics approaches to improve bioenergy traits in maize, sorghum and sugarcane. Journal of Integrative Plant Biology, 53, pp. 105-119, 2011. https://doi:10.1111/j.1744-7909.2010. 01020.x

[6] Feltus, F.A., \& Vandenbrink, J.P., Bioenergy grass feedstock: current options and prospects for trait improvement using emerging genetic, genomic, and systems biology toolkits. Biotechnology for Biofuels 5, Article Number: 80, 2012. https:// doi:10.1186/1754-6834-5-80

[7] Jordan, D., et al., Plant cell walls to ethanol. The Biochemical Journal, 442(2), pp. 241-252, 2012. https://doi:10.1042/BJ20111922

[8] Nookaraju, A., Pandey, S.K., Bae, H.J. \& Joshi, C.P., Designing cell walls for improved bioenergy production. Molecular Plant, 6, pp. 8-10, 2013. https://doi:10.1093/mp/ sss 111

[9] Demirbas, A., Combustion characteristics of different biomass fuels. Progress In Energy and Combustion Science, 30, pp. 219-230, 2004. https;//doi:10.1016/j.pecs.2003.10.004

[10] Goyal, H.B., Seal, D. \& Saxena, R. C., Bio-fuels from thermochemical conversion of renewable resources: a review. Renewable and Sustainable Energy Reviews, 12, pp. 504-517, 2008. https://doi:10.1016/j.rser.2006. 07.014

[11] Tanger, P., Field, J.L., John, C.E., DeFoot, M.W.\& Leach, J.E.,Biomass for thermochemical conversion: targets and challenges. Frontier in Plant Science, July 2013, https://doi.org/10.3389/fpls.2013.00218

[12] Butler, E., Devlin, G., Meier, D. \& McDonnell, K., A review of recent laboratory research and commercial developments in fast pyrolysis and upgrading. Renewable and Sustainable Energy Reviews, 15, pp. 4171-4186, 2011. https://doi:10.1016/j.rser.2011. 07.035 
[13] Wang, M.Q., Han, J., Haq, Z., Tyner, W.E., Wu, M., \& Elgowainy, A., Energy and greenhouse gas emission effects from corn and cellulosic ethanol with technology improvements and land-use changes. Biomass and Bioenergy, 35, pp. 1885-1896, 2011. https:// doi:10.1016/j.biombioe.2011.01.028

[14] Brar, J.S., Singh, K., Wang, J. \& Kumar, S., Cogasification of coal and biomass: A Review. International Journal of Forestry Research, Article ID: 363058, 2012. https:// doi:10.1155/2012/363058

[15] Bridgwater, A.V., Review of fast pyrolysis of biomass and product upgrading. Biomass and Bioenergy, 38, pp. 68-94, 2012. https://doi:10.1016/j.biombioe.2011.01.048

[16] Solantausta, Y., Oasmaa, A., Sipilä, K., Lindfors, C., Lehto, J., Autio, J., et al., Biooil production from biomass: Steps toward Demonstration. Energy \& Fuels, 26, pp. 233-240, 2012. https://doi:10.1021/ef201109t

[17] Gaul, M., An analysis model for small-scale rural energy service pathways-Applied to Jatropha-based energy services in Sumbawa, Indonesia. Energy for Sustainable Development, 16, pp. 283-296, 2012. https://doi:10.1016/j.esd.2012.05.001

[18] Robbins, M.P., Evans, G., Valentine, J., Donnison, I.S. \& Allison, G.G., New opportunities for the exploitation of energy crops by thermochemical conversion in Northern Europe and the UK. Progress in Energy and Combustion Science, 38, pp. 138-155,2012. httpss://doi.org/10.1016/j.pecs.2011.08.001

[19] Das, B., Characterisation of Biomass/Agro Residues and Application of Selected Biomass for Sorption of Phenol from Aqueous Solutions. PhD Theses submitted to SLIET University, Longowal, India, 2016.

[20] Miles, T.R., MilesJr, T.R., Baxter, L. L., Bryers, R.W., Jenkins, B. M., \& Oden, L.L., Boiler deposits from firing biomass fuels. Biomass and Bioenergy, 10, pp. 125-138, 1996. https://doi:10.1016/0961-9534(95)00067-4

[21] Jenkins, B.M., Baxter, L.L., Miles, T.R.Jr., \& Miles, T.R., Combustion properties of biomass. Fuel Processing Technology, 54, pp. 17-46, 1998. https://doi:10.1016/S03783820(97)00059-3

[22] Riley, J.T., Manual57 Routine Coal and Coke Analysis: Collection, Interpretation, and Use of Analytical Data. West Conshohocken, PA: ASTM International, 2007.

[23] Gartner, B.L. \& Meinzer, F.C., Structure-Function Relationships in Sapwood Water Transport and Storage. Vascular Transport in Plants, pp. 307-331, 2005. https;//doi. org/10.1016/B978-012088457-5/50017-4

[24] Claudia Juliana Gomez Diaz, Understanding Biomass Pyrolysis Kinetics: Improved Modelling Based on Comprehensive Thermo Kinetic Analysis, PhD Theses, submitted to Universidad Polytechnic de Catalunya, 2006.

[25] Fahmi, R., Bridgwater, A.V., Donnison, I.., Yates, N. \& Jones J.M., The effect of lignin and inorganic species in biomass on pyrolysis oil yields, quality and stability. Fuel, 87, pp. 1230-1240, 2008. https:// doi:10.1016/j.fuel.2007.07.026

[26] Jha, P., Biomass Characterization and Application of Biomass Char for Sorption of Phenol from Aqueous Solutions. PhD Theses submitted to Indian Institute of Technology, Delhi, 1996. 